Available online at GSC Online Press Directory

GSC Biological and Pharmaceutical Sciences

e-ISSN: 2581-3250, CODEN (USA): GBPSC2

Journal homepage: https://www.gsconlinepress.com/journals/gscbps

(RESEARCH ARTICLE)

\title{
Antibacterial and antifungal activities of hexane and acetone extracts of sheets and fruits of Feijoa sellowiana 0.
}

\author{
Elfarnini M. ${ }^{1}$, Abdel-hamid A.A. ${ }^{1}$, Achir M. ${ }^{2}$, Jamaleddine J. ${ }^{2}$ and Blaghen M. ${ }^{1}$ \\ ${ }^{1}$ Laboratory of Microbiology, Pharmacology, Biotechnology and Environment, Faculty of Sciences Aïn Chock, Hassan II \\ University, ElJadida Street, B.P. 5366 Mâarif, Casablanca, Morocco. \\ ${ }^{2}$ Laboratory of Chemistry and Molecular biology, Faculty of Sciences, Aïn Chock, Hassan II University, ElJadida Street, B.P. \\ 5366 Mâarif, Casablanca, Morocco.
}

Publication history: Received on 22 March 2018; revised on 11 April 2018; accepted on 13 April 2018

https://doi.org/10.30574/gscbps.2018.3.1.0024

\begin{abstract}
In these last decades, recent pharmacopeia was focused on the search of bioactive molecules, which were extracted from medicinal plants. In this study, our choice related to Moroccan variety Feijoa sellowiana (F. sellowiana). Because, this variety had not been scientifically evaluated yet. Meanwhile, its fruits were ignored by moroccan population, which could economically constitute an exploitable source. Thus, the objective of this study was to evaluate the microbial activities of $F$. sellowiana. Extraction was carried out by successive exhaustion of plant materials, by using two organic solvents, hexane and acetone. Therefore, the separation of each extract was done using chromatography on column. Thereafter, the screening of secondary metabolites were done by the method of screening. According to the different results obtained during this study. All extracts have showed the presence of secondary metabolites such as saponosids, tannins, steroids and terpens. Thus, they showed antimicrobial activities except acetone extract of fruits, almost all fractions revealed as inactives on Candida albicans. However, more studies are needed to valorize the moroccan variety F. sellowiana and could be used to overcome the microbial aggressions.
\end{abstract}

Keywords: Feijoa sellowiana 0.; Antibacterial; Antifungal; Hexane extract; Acetone extract

\section{Introduction}

In order to deal with the drug resistance of microorganisms in patients, scientific researchers directed their research toward the traditional pharmacopeia in the objective of discovering other molecules having a biological activity, being able to precisely face the development of the infectious diseases in the world in general and countries in the process of development like Morocco.

Since antiquity, man seeks to overcome the microbial aggressions by using innumerable mixtures of extract of plants. However with the arrival of technology, these mixtures were transformed into composed purely chemical having adverse effects which were harmful for man's health. This had made a strong return back to the traditional pharmacopeia, considering its accessibility and its lower cost. Moreover, the World Health Organization (WHO) estimated in 2007 that approximately $80 \%$ of the population of countries in the process of development could be neat starting from the plants [1-3]. In 2001, several tests carried out on Spleens, revealed that $25 \%$ of regulation in the world of drugs and, 60 to $70 \%$ of substances which had antibacterial and anti-cancer effects, had been extracted from plants [4-5]. In this study, our choice related to the exotic fruit moroccan Feijoa sellowiana (F. sellowiana) because, this moroccan variety had not been scientifically evaluated yet. Therefore, its fruit were ignored by moroccan population,

\footnotetext{
${ }^{*}$ Corresponding author

E-mail address: dourgo7@ gmail.com
}

Copyright (C) 2018 Author(s) retain the copyright of this article. This article is published under the terms of the Creative Commons Attribution Liscense 4.0. 
which could economically constitute an exploitable source. This plant pertaining to Myrtaceae, it could be found in subtropical countries with moderate climate. F. sellowiana could resist dryness, but in culture, it required to be irrigated for best production of hight quality of fruits. A clay-sand ground, rich in humus, proved to be the best ground for this plant. It could be however satisfied in a poor ground, which was well-drained [6].

This shrub measured 5 to 8 meters, sometimes a buissonnant shrub, with a bark pale brown gray, gray branches and a silver plated foliage with gray reflection. Its fruits were in ovoid form with an average of weight between 25 to 60 grams and length between 5 to $8 \mathrm{~cm}$. [7]. Several studies were conducted to evaluate the biological activities of this plant. Until now, published papers revealed several biological effects of a great interest among which antimicrobial activities.

Vuotto and its collaborators published several articles on component bioactifs contained in the extract of this plant, which showed an antibacterial activity. The aqueous extract of fruits of this plant could be a drug with multiple facets [8-10]. Meanwhile, other studies were also revealed some activities such as anti-inflammatory drug, anti-cancer and anti-depressive. Thus, this work will be focused on antimicrobial and antifungal activities of F. sellowiana.

\section{Material and methods}

\subsection{Plant material}

Sheets and fruits of F. sellowiana were collected in September and November 2017 in Casablanca.

\subsection{Microorganism used}

The provided Strains used in this study were: Staphylococcus aureus (S. aureus) ATCC 25923, Escherichia coli (E. coli) CIP 54127, Pseudomonas aeruginosa (P. aeruginosa) CIP A 22, Bacillus cereus (B. cereus) IPL141, Candida albicans (C. albicans) ATCC 90028.

\subsection{Preparation of extracts}

The extraction was carried out by successive exhaustion of plant materials, by using two organic solvents, hexane and acetone, with increasing polarity. $116 \mathrm{~g}$ of fruits of $F$. sellowiana were crushed and piled up in a cartridge which was deposited in the Soxhlet device with $200 \mathrm{ml}$ of solvent for each extraction. Once the extraction was finished solvents were eliminated by evaporation using a rotary evaporator under reduced pressure to avoid any degradation of existing compounds in the extract. Obtained extracts were kept at $4^{\circ} \mathrm{C}$ before analysis. The same procedure was applied using $55 \mathrm{~g}$ of sheets of the plant.

\subsection{Phytochemical screening}

Secondary metabolites of each extract were screened by the method of screening according to the standard procedures [16].

\subsection{Separation using chromatography on column}

Extracts of fruits and sheets of $F$. sellowiana were the object of separation by chromatography on column by using silica gel in the stationary phase $(2 \mathrm{~cm}$ x $20 \mathrm{~cm})$. Elution was carried out by using hexane and acetone. Therefore, obtained fractions underwent an evaporation to eliminate organic solvents, there after they were kept at $4{ }^{\circ} \mathrm{C}$ before analysis.

\subsection{Antibacterial and antifungal activities}

Antimicrobial activities were evaluated by the method of diffusion on agar and microdilution on microplate, in order to calculate minimum inhibitory concentration (MIC) and minimum bactericidal concentration (MBC) of fractions of various extracts obtained.

\subsubsection{Liquid medium}

Liquid Mueller Hinton Broth (MHB): contained, beef infusion solids, casein hydrolysate and starch, their quantities were $2.0 \mathrm{~g}, 17.5 \mathrm{~g}$ and $1.5 \mathrm{~g}$ in $1 \mathrm{~L}$ of distilled water. Final $\mathrm{pH}, 7.4 \pm 0.2\left(25^{\circ} \mathrm{C}\right)$.

Liquid Extract-Peptone-Glycerol (YPG): contained, bacto yeast extract, bacto peptone, glycerol, bacto agar, their quantities were $10 \mathrm{~g}, 20 \mathrm{~g}, 30 \mathrm{ml}, 20 \mathrm{~g}$ in $1 \mathrm{~L}$ of distilled water. Final pH, $7.4 \pm 0.2\left(25^{\circ} \mathrm{C}\right)$. All products were purchased from Biokar Diagnostics [11-15]. 


\subsubsection{Innoculums preparation}

All stains used in this study were kept at $4{ }^{\circ} \mathrm{C}$ prior analysis. Liquid cultures were prepared and incubated at $37{ }^{\circ} \mathrm{C}$ for $24 \mathrm{~h}$ and solid culture sown on Petri limp and incubated at $37^{\circ} \mathrm{C}$ for $24 \mathrm{~h}$, for making sure the purity of cultures. These limps were used to prepare inoculums of bacteria. Meanwhile, liquid YPG medium was prepared and incubated at $30{ }^{\circ} \mathrm{C}$ for $24 \mathrm{~h}$ and added agar, before sown on Petri limp and incubated at $30^{\circ} \mathrm{C}$ for $24 \mathrm{~h}$. These limps were used to prepare the inoculums of $C$. albicans.

\subsubsection{Disc diffusion method}

The inhibition of microbial growth by different extracts of fruits and sheets, was evaluated by the method of diffusion on discs.

In this method, filter paper discs $6 \mathrm{mms}$ in diameter which impregnated by a known volume of the substance to test, were deposited on the surface of an agar medium sown before hand surfaces by $0.1 \%$ of overnight microbial suspension. After incubation, the reading of the results was done by measurement of the diameter of zones of inhibition (ZI) in millimeters (mm) [17-19].

\subsubsection{Determination of MIC using micro-dilution method}

MIC was given by the method of microdilution. Into 96 wells of microplaque, $50 \mu \mathrm{l}$ of MHB medium were introduced, except the wells of the first column, where $100 \mu \mathrm{l}$ of each extract to be tested were deposited, then of successive dilutions of a factor of 2 were realized to the wells of the $11^{\text {th }}$ column. The last column was regarded as positive witness of growth (absence of extract). The inoculation was made by $50 \mu \mathrm{l}$ of the inoculum prepared before hand. The microplates ones were incubated with $37^{\circ} \mathrm{C}$ for $24 \mathrm{~h}$. Thereafter, the first concentration of which no bacterial growth was noted and counted its MIC $[20,21]$. Each test was reproduced 3 times.

\subsubsection{Determination of $M B C$}

MBC was the lowest concentration of an extract which leaving at most $0.01 \%$ survivor germs. MBC of each extract was analyzed by taking $3 \mu \mathrm{l}$ from wells which were shown as negative (no growth), started from wells of MIC, and sowed using spot on MHA medium, thereafter limps were incubated at $37^{\circ} \mathrm{C}$ for $24 \mathrm{~h}$.

\section{Results and discussion}

\subsection{Extraction using Soxhlet method}

Various raw organic extracts of air parts quoted above, were prepared by exhaustion hot vegetable materials using hexane and acetone according to their increasing polarity. Outputs obtained were illustrated in Fig. 1.

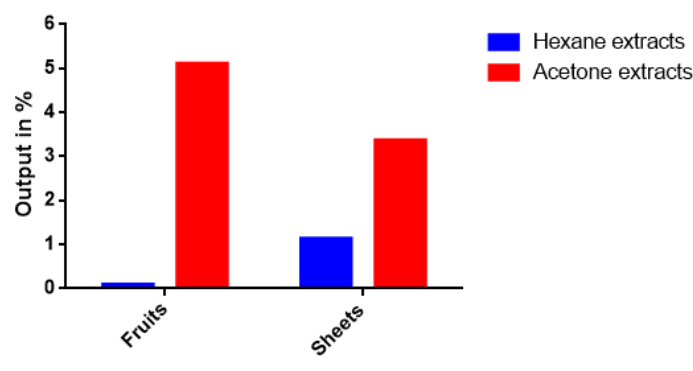

Figure 1 Output of hexane and acetone extracts

The highest output obtained was, acetone extracts which were 5.11\% (5,11 g) and 3.37\% (3,37 g) for sheets and fruits respectively compared to hexane extracts which were given $1.14 \%(0,63 \mathrm{~g})$ and $0.09 \%(0,104 \mathrm{~g})$ for sheets and fruits respectively. Meanwhile, results of hexane extracts were comparable with those obtained by Nakashima (2001), but the value of hexane extract of fruits was $0.1 \%$ [22]. whereas, values of acetone extract were different from other values published by Motohashi et al. (2000), which was around 1.96\% [23].

From polarity point of view, highest outputs were polar extracts (acetone) compared to non-polar extracts (hexane). these results reflected low content of lipids in sheets and fruits. 


\subsection{Separation using chromatography on column}

Extracts obtained by soxhlet underwent a chromatography on column, and followed-up by Thin layer chromatography, to get fractions had same chemical compounds. Thus several fractions were recovered for each extract. Chromatography on column separation, fractions were visually given by color change. Raw hexane extract of fruits was given three fractions $\mathrm{H}_{1}-\mathrm{H}_{3}$, whereas that of sheets was given four fractions $\mathrm{H}_{1}-\mathrm{H}_{4}$. Meanwhile, acetone extracts of fruits and sheets were given three fractions $\mathrm{A}_{1}-\mathrm{A}_{4}$.

\subsection{Phytochemical screening}

To determine secondary metabolites of each extract, which were responsible of biological activities, screening method was used according to the standard procedures [24]. Results were indexed in Table 1.

Table 1 The presence and absence of secondary metabolites in extracts

\begin{tabular}{|c|c|c|c|c|}
\hline \multirow{2}{*}{ Phytoconstituents } & \multicolumn{2}{|c|}{ Sheets } & \multicolumn{2}{|c|}{ Fruits } \\
\hline & Hexane extract & Acetone extract & Hexane extract & Acetone extract \\
\hline Saponoside & - & + & - & - \\
\hline Tanin & - & + & - & + \\
\hline Steroid & + & + & + & - \\
\hline Terpene & + & + & - & + \\
\hline Flavonoid & - & - & - & - \\
\hline Coumarine & + & - & + & + \\
\hline
\end{tabular}

In the case of sheets extracts, both secondary metabolites steroid and terpene were present in acetone and hexane extracts, whereas tannin and saponoside were just present in hexane extract, and coumarine was just in acetone extract. In the case of fruits extracts, coumarine was present in both hexane and acetone extracts, meanwhile tannin and terpene were just present in acetone extract, and steroid was just in hexane extract. Therefore, steroid, terpene and coumarine were highlighted in almost all extracts except, in acetone and hexane extract of fruits, and in acetone extract of sheets respectively. Thereafter, tannin was present in both of acetone exracts and saponoside was just in extract of sheets. These results were comparable with those published earlier, indeed, Monforte et al. (2014) and Weston (2010) identified saponins, tannins, steroids,terpenes, flavonoids and coumarines among other components in extracts of $F$. sellowiana $[25,26]$.

\subsection{Antibacterial and Antifungal activities}

Antibacterial activities of fractions of all extracts of $F$. sellowianaw were carried out on referenced microbial strains. Results were represented in Table 2 and Table 3.

Raw hexane extract of fruit $\left(\mathrm{H}_{0}\right)$ was active on four bacterial strains tested. Indeed, ZIs were 13.5, 14, 12 and $13 \mathrm{~mm}$ on E. coli, P. aeruginosa, B. cereus and S. aureus respectively.

Whereas the fraction $\mathrm{H}_{1}$ of hexane extract of fruits showed an average activity with ZI of $13 \mathrm{~mm}$ on $E$. coli, and a weak activity on $S$. aureus was $(9 \mathrm{~mm})$. However the 2 nd fraction was slightly active on three strains E. coli, P. aeruginosa, and $S$. aureus with some 12,10 and $10.5 \mathrm{~mm}$ respectively. Meanwhile, fraction $\mathrm{H}_{3}$ of hexane extract of fruits didn't show an activity on all strains and on C. albicans.

Raw hexane extract of sheets revealed antibacterial effects on all four strains. Diameters of ZIs were 12.5, 14, 12 and $13 \mathrm{~mm}$ on E. coli, P. aeruginosa, B. cereus and $S$. aureus respectively. $\mathrm{H}_{1}$ fraction showed a weak activity against $B$. cereus $(10 \mathrm{~mm})$ whereas it was inactive on other three strains. For $\mathrm{H}_{2}$ fraction ZIs were 10, 14, 11 et $11.5 \mathrm{~mm}$ on E. coli, $P$. aeruginosa, B. cereus and $S$. aureus respectively. Whereas the 3rd fraction proved to be very active on all strains, with diameters of ZIs 26, 15, 18, and $24 \mathrm{~mm}$ on E. coli, P. aeruginosa, B. cereus and S. aureus respectively. With regard to $\mathrm{H}_{4}$ fraction didn't show an activity on all strains.

For the antifungal effect, in the case of hexane extract of sheets. $\mathrm{H}_{2}$ and $\mathrm{H}_{3}$ fractions were active on C. albicans, with diameters of ZIs $13,10.5$ and $25 \mathrm{~mm}$ respectively. 
Table 2 Diameter of zones of inhibition, obtained by fractions of hexane extracts of fruits and sheets, and raw hexane extract

\begin{tabular}{lccccc}
\hline Fractions & E. coli & P. aeruginosa & B. cereus & S. aureus & C. albicans \\
\hline & \multicolumn{5}{c}{ Fractions of hexane extract of } \\
$\mathrm{H}_{0}$ & 13.5 & 13 & 12 & 12 & - \\
$\mathrm{H}_{1}$ & 13 & - & - & 9 & - \\
$\mathrm{H}_{2}$ & 12 & 10 & - & 10.5 & - \\
$\mathrm{H}_{3}$ & - & - & - & - & - \\
\hline
\end{tabular}

\begin{tabular}{cccccc}
\hline \multicolumn{5}{c}{ Fractions of hexane extract of sheets } \\
$\mathrm{H}_{0}$ & 12.5 & 14 & 12 & 13 & 13 \\
$\mathrm{H}_{1}$ & - & - & 10 & - & - \\
$\mathrm{H}_{2}$ & 10 & 14 & 11 & 11.5 & 10.5 \\
$\mathrm{H}_{3}$ & 26 & 15 & 18 & 24 & 25 \\
Results expressed in millimeter $(\mathrm{mm}) . \mathrm{H}$ : Raw hexane extract of fruits and sheets. $\mathrm{H}_{1}, \mathrm{H}_{2}, \mathrm{H}_{3}, \mathrm{H}_{4}:$ Fractions of hexane extract of fruits and sheets.
\end{tabular}

These antimicrobial effects could be allotted to chemical compositions of hexane extracts which would be riched in terpenes, steroids and coumarines, whose antimicrobial capacity was shown considerable, Nakashima (2001). The evaluation of antimicrobial activities of fractions of hexane extract of fruits of $F$. sellowianaw was carried out by Nakashima (2001). Its results agree with our antibacterial results, whereas they were different compared to antifungal results. Indeed, results of Nakashima showed antibacterial activities of hexane fractions on E. coli and S. epidermidis, and an important activity of the fraction $\mathrm{H}_{2}$ on C. albicans.[22].

Table 3 Diameter of zones of inhibition, obtained by fractions of acetone extracts of fruits and sheets, and raw acetone extract

\begin{tabular}{|c|c|c|c|c|c|}
\hline \multirow[t]{2}{*}{ Fractions } & E. coli & P. aeruginosa & B. cereus & S. aureus & C. albicans \\
\hline & \multicolumn{5}{|c|}{ Fractions of acetone extract of fruits } \\
\hline A0 & 20 & 19 & 13 & 23 & - \\
\hline A1 & 22 & 18 & 13 & 19 & - \\
\hline A2 & 16.5 & 13 & 16 & 20 & 10 \\
\hline \multirow[t]{2}{*}{ A3 } & 25 & 17 & 26 & 22 & - \\
\hline & \multicolumn{5}{|c|}{ Fractions of acetone extract of sheets } \\
\hline A0 & 19 & 25 & 21 & 15 & 20 \\
\hline A1 & 17.5 & 12 & 13 & - & - \\
\hline A2 & - & - & 14 & - & 23 \\
\hline A3 & 18 & 16 & - & 19 & 13.5 \\
\hline
\end{tabular}

In the case of raw acetone extract of fruits $\left(A_{0}\right)$, it was active on four bacterial strains. Diameter of ZIs were 20, 19, 13 and $23 \mathrm{~mm}$ respectively on E. coli, P. aeruginosa, B. cereus and S. aureus; $\mathrm{A}_{1}$ fraction of the same extract showed an important activity with diameters of 22, 18, 13 and $19 \mathrm{~mm}$ on E. coli, P. aeroginosa, B. cereus and S. aureus respectively. Whereas, $A_{2}$ fraction was more active on $S$. aureus $(20 \mathrm{~mm})$, followed by E. coli $(16.5 \mathrm{~mm})$, B. cereus $(16 \mathrm{~mm})$ and $P$. aeruginosa $(13 \mathrm{~mm}) . A_{3}$ fraction of acetone extract of fruits was the most active compared to three other fractions. Thus, it was active on all strains, diameter of ZIs were 25, 17, 26 and $22 \mathrm{~mm}$ on E. coli, P. aeruginosa, B. cereus et S. aureus respectively. 
For the antifungal effects, all fractions revealed as inactives, unless $A_{2}$ fraction recorded a weak activity with the diameter of $10 \mathrm{~mm}$.

In the case of raw acetone extract of sheets $\left(A_{0}\right)$, it was largely active on all bacterial strains. Diameter of ZIs $19,25,21$ and $15 \mathrm{~mm}$ on E. coli, P. aeruginosa, B. cereus and S. aureus respectively.

The $1^{\text {st }}$ fraction showed an average activity with respect on $P$. aeruginosa $(12 \mathrm{~mm})$ and $B$. cereus $(13 \mathrm{~mm})$, whereas it was very active on $E$. coli $(17.5 \mathrm{~mm})$. The $\mathrm{A}_{2}$ fraction of the same extract had an activity on B. cereus $(14 \mathrm{~mm})$. Bacterial activities of the $3^{\text {rd }}$ fraction were noticed on E. coli, P. aeruginosa and S. aureus with diameter of ZIs of 18,16 and $19 \mathrm{~mm}$ respectively.

For the antifungal effects in the case of acetone extract of sheets, $A_{0}$ and $A_{2}$ fractions had a remarkable effects on $C$. albicans with diameters of 20 and $23 \mathrm{~mm}$ respectively, whereas the $3^{\text {rd }}$ fraction was fairly active with the diameter of $13.5 \mathrm{~mm}$.

According to the analysis of these results, it arose that acetone extracts have a antibacterial and antifungal activities which their effectiveness varies from a fraction to another. In addition, the phytochemical sifting of the raw acetone extracts showed the presence of secondary metabolites such as saponosids, tannins, steroids and terpens which their antimicrobial activities were already confirmed.

Our results were on the same track with that of Motohashi and Al, (2000). Indeed their study carried on the antimicrobial activities of $F$. sellowiana which revealed antimicrobial activities of fractions of acetone extracts of fruits on E. coli, P. aeruginosa, S. epidermidis and C. albicans. In the same way, another study of antibacterial effects of acetone extracts of sheets proved their capacity of inhibition on E. coli, P. aeruginosa and S. aureus [23].

\subsection{Microdilution}

Results of MIC of hexane and acetone fractions of $F$. sellowiana, obtained by microdilution were illustrated in Table 4 and 5 .

Table 4 MIC of hexane fraction of fruits and sheets, and raw hexane extract

\begin{tabular}{|c|c|c|c|c|}
\hline \multirow[t]{2}{*}{ Fractions } & \multicolumn{4}{|c|}{ MIC in \% } \\
\hline & E. coli & P. aeruginosa & B. cereus & S. aureus \\
\hline & \multicolumn{4}{|c|}{ Fractions of hexane extract of fruits } \\
\hline $\mathrm{H}_{0}$ & 20 & 40 & 40 & 40 \\
\hline $\mathrm{H}_{1}$ & 40 & - & - & 20 \\
\hline \multirow{2}{*}{$\mathrm{H}_{2}$} & 20 & 2.5 & - & 20 \\
\hline & \multicolumn{4}{|c|}{ Fractions of hexane extract of sheets } \\
\hline $\mathrm{H}_{0}$ & 40 & 20 & 40 & 10 \\
\hline $\mathrm{H}_{1}$ & - & - & 20 & - \\
\hline $\mathrm{H}_{2}$ & 20 & 40 & 20 & 20 \\
\hline $\mathrm{H}_{3}$ & 5 & 10 & 40 & 40 \\
\hline
\end{tabular}

The result of MIC of raw $\left(\mathrm{H}_{0}\right)$ and fractions of hexane extract of fruits obtained, showed different values between $2.5 \%$ to $40 \%(\mathrm{v} / \mathrm{v})$, whereas those of sheets were between $5 \%$ to $40 \%(\mathrm{v} / \mathrm{v}) . \mathrm{H}_{2}$ fraction of fruits showed a significant inhibition on P. aeruginosa sight its value was $2.5 \%(\mathrm{v} / \mathrm{v})$ and on E. coli showed the value of $20 \%$ (v/v) which was identical when used the raw extract $\left(\mathrm{H}_{0}\right)$. this last value also appeared on $S$. aureus when used $\mathrm{H}_{1}$ and $\mathrm{H}_{2}$ fractions of the same extract. Therefore, the raw extract $\left(\mathrm{H}_{0}\right)$ of the same extract revealed similar inhibitions on $P$. aeruginosa, B. cereus and $S$. aureus the value was $40 \%(\mathrm{v} / \mathrm{v})$, and on $E$. coli appeared the same value when used $\mathrm{H}_{1}$ fraction.

In the case of hexane extract of sheets, the $\mathrm{H}_{3}$ fraction gave the most remarkable effect which was $5 \%$ (v/v) on $E$. coli, therefore, on this last stain the MIC was $20 \%$ (v/v) when used $\mathrm{H}_{2}$ fraction. Meanwhile, $\mathrm{H}_{3}$ fraction had showed the value of $10 \%(\mathrm{v} / \mathrm{v}$ ) which was sufficient to inhibit P. aeruginosa. Whereas, on this last stain the MIC was $20 \%$ (v/v) when used $\mathrm{H}_{0}$ fraction and $40 \%(\mathrm{v} / \mathrm{v})$ when used $\mathrm{H}_{2}$ fraction. $\mathrm{H}_{3}$ and $\mathrm{H}_{0}$ fractions showed identical MIC (40\% (v/v)) on B. cereus. Therefore, on this last train revealed another similar MIC which was $20 \%(\mathrm{v} / \mathrm{v})$ when used H1 and H2 fractions. 
Thereafter, on the strain S. aureus revealed an important inhibition which was $10 \%$ (v/v), fallowed by $20 \%$ (v/v) and $40 \%\left(\mathrm{v} / \mathrm{v}\right.$ ) when used $\mathrm{H}_{0}, \mathrm{H}_{2}$ and $\mathrm{H}_{3}$ fractions respectively.

Table 5 MIC of acetone fractions of fruits and sheets, and raw acetone extract

\begin{tabular}{llccc}
\hline Fractions & \multicolumn{2}{c}{ MIC in \% } & S. aureus \\
\hline & & E. coli & Fractions of acetone extracts of fruits \\
$\mathrm{A}_{0}$ & 40 & 10 & 5 & 10 \\
$\mathrm{~A}_{1}$ & 5 & 10 & 40 & 40 \\
$\mathrm{~A}_{2}$ & 10 & 40 & 40 & 10 \\
$\mathrm{~A}_{3}$ & 40 & 20 & 20 & 20 \\
\hline & & Fractions of acetone extracts of sheets & \\
$\mathrm{A}_{0}$ & 20 & 40 & 10 & 20 \\
$\mathrm{~A}_{1}$ & 10 & 20 & 40 & - \\
$\mathrm{A}_{2}$ & - & - & 40 & - \\
$\mathrm{A}_{3}$ & 20 & 10 & - & 40 \\
\hline
\end{tabular}

The test of microdilution revealed values of MIC were between $5 \%(\mathrm{v} / \mathrm{v})$ to $40 \%(\mathrm{v} / \mathrm{v})$ for fractions of acetone raw extracts of fruits. Whereas MIC results of fractions of acetone raw extracts of sheets showed were between $10 \%(\mathrm{v} / \mathrm{v}$ ) to $40 \%(\mathrm{v} / \mathrm{v})$.

In the case of acetone extracts of fruits, the effect of $A_{1}$ fraction was more accentuated with MIC of 5\% (v/v), $A_{2}$ fraction with $10 \%(\mathrm{v} / \mathrm{v})$, the raw extract $\left(\mathrm{A}_{0}\right)$ and $\mathrm{A}_{3}$ fractions with $40 \%(\mathrm{v} / \mathrm{v})$ on E. coli.

The inhibition of $P$. aeruginosa was made by concentrations of $10 \%$ for $A_{0}$ and $A_{1}$ fractions, and $20 \%(v / v), 40 \%(v / v)$ for $A_{3}$ and $A_{2}$ fractions respectively. In the case of $B$. cereus, the inhibition of $A_{0}$ fraction with the value of $5 \%(v / v)$ was significant, followed by the value of $20 \%(\mathrm{v} / \mathrm{v})$ for $\mathrm{A}_{3}$ fraction and $40 \%(\mathrm{v} / \mathrm{v})$ for $\mathrm{A}_{1}$ and $\mathrm{A}_{2}$ fractions. However, the inhibition of $S$. aureus was made by a concentration of $10 \%(\mathrm{v} / \mathrm{v})$ for the raw extract and $\mathrm{A}_{2}$ fraction, followed by a concentration of $20 \%$ for $\mathrm{A}_{3}$ fraction and $40 \%$ for $\mathrm{A}_{1}$ fraction. The test of determination of MIC of extract $\mathrm{A}_{0}$ of fruit by Basile and al. (2010), gave values of MIC variable from 3.9 to $62.5 \mu \mathrm{g} / \mathrm{ml}$. In another study published in 1997, Basile et al. deferred that concentrations going from 4 to $64 \mu \mathrm{g} / \mathrm{ml}$ were sufficient to inhibit the growth of $P$. aeruginosa, E. coli and $S$. aureus $[7,27]$.

\subsection{Determination of MBC}

MBC of acetone and hexane extracts of sheets and fruits, were illustrated in the tables below (tables 6 and 7).

Table $6 \mathrm{MBC}$ of hexane fractions and raw hexane extract

\begin{tabular}{|c|c|c|c|c|}
\hline \multirow[t]{2}{*}{ Fractions } & \multicolumn{4}{|c|}{ MBC in \% } \\
\hline & E. coli & P. aeruginosa & B. cereus & S. aureus \\
\hline & \multicolumn{4}{|c|}{ Fractions of hexane extract of fruits } \\
\hline $\mathrm{HO}$ & 40 & 80 & 80 & 80 \\
\hline $\mathrm{H} 1$ & 80 & - & - & 40 \\
\hline \multirow{2}{*}{$\mathrm{H} 2$} & 40 & 5 & - & 40 \\
\hline & \multicolumn{4}{|c|}{ Fractions of hexane extract of sheets } \\
\hline $\mathrm{HO}$ & 80 & 40 & 80 & 20 \\
\hline $\mathrm{H} 1$ & - & - & 40 & - \\
\hline $\mathrm{H} 2$ & 40 & 80 & 40 & 20 \\
\hline $\mathrm{H} 3$ & 10 & 20 & 80 & 80 \\
\hline
\end{tabular}


Table $7 \mathrm{MBC}$ of acetone fractions and raw acetone extract

\begin{tabular}{lllll}
\hline \multirow{2}{*}{ Fractions } & \multicolumn{4}{c}{ MBC in \% } \\
& E. coli & $\boldsymbol{P}$. aeruginosa & B. cereus & S. aureus \\
\hline \multicolumn{5}{c}{ Fractions of acetone extract of fruits } \\
A0 & 80 & 20 & 10 & 20 \\
A1 & 10 & 20 & 80 & 80 \\
A2 & 20 & 80 & 80 & 20 \\
A3 & 80 & 40 & 40 & 40 \\
\hline \multicolumn{5}{c}{ Fractions of acetone extract of sheets } \\
A0 & 40 & 80 & 20 & 40 \\
A1 & 20 & 40 & 80 & - \\
A2 & - & - & 80 & - \\
A3 & 40 & 20 & - & 80 \\
\hline
\end{tabular}

The values of the MBC of fractions and raw extracts tested, were higher than those of the MIC. Results showed bacterial activities of organic extracts tested against studied germs. These results are in agreement with those stated by Vutto et al. (2000), Basile et al. (2010 and 1997) [27, 8].

\section{Conclusion}

According to the different results obtained during this study, the highest output obtained, was the acetone extracts compared to hexane extracts. All extracts have showed the presence of secondary metabolites such as saponosids, tannins, steroids and terpens. Thus, they showed antimicrobial activities except acetone extract of fruits, almost all fractions revealed as inactives on $C$. albicans. However, more studies are needed to valorize the moroccan variety $F$. sellowiana and could be used to overcome the microbial aggressions.

\section{Compliance with ethical standards}

\section{Acknowledgments}

This work was supported in part by Health and Biotechnology center and Casablanca Hassan II University.

\section{Disclosure of conflict of interest}

The authors have declared that no competing interest exists.

\section{References}

[1] Pan SY, Zhou SF, Gao SH, Yu ZL, Zhang SF, Tang MK, Sun JN, Ma DL, Han YF, Fong WF and Ko KM. (2013). New perspectives on how to discover drugs from herbal medicines: CAM's outstanding contribution to modern therapeutics. Evidence-Based Complementary and Alternative Medicine, 2013.

[2] Global Initiative for Traditional Systems (GIFTS) of Health. (1997). Medicinal plants for forest conservation and health care. Food and Agriculture Organization, 92.

[3] Konaté K, Mavoungou JF, Lepengué AN, Aworet-Samseny RR, Hilou A, Souza A, Dicko MH and M’Batchi B. (2012). Antibacterial activity against $\beta$-lactamase producing Methicillin and Ampicillin-resistants Staphylococcus aureus: fractional Inhibitory Concentration Index (FICI) determination. Annals of clinical microbiology and antimicrobials, 11(1), 18.

[4] Rates SMK. (2001). Plants as source of drugs. Toxiconology, 39(5), 603-613.

[5] Amin A, Gali-Muhtasib H, Ocker M and Schneider-Stock R. (2009). Overview of major classes of plant-derived anticancer drugs. International journal of biomedical science: IJBS, 5(1), 1. 
[6] Akin M, Aktumsek A and Nostro A. (2010). Antibacterial activity and composition of the essential oils of Eucalyptus camaldulensis Dehn and Myrtus communis L. growing in Northern Cyprus. African Journal of Biotechnology, 9(4).

[7] Basile A, Vuotto ML, Violante U, Sorbo S, Martone G and Castaldo-Cobianchi R. (1997). Antibacterial activity in Actinidia chinensis, Feijoa sellowiana and Aberia caffra. International Journal of Antimicrobial Agents, 8(3), 199203.

[8] Vuotto ML, Basile A, Moscatiello V, De Sole P, Castaldo-Cobianchi R, Laghi E and Ielpo MT. (2000). Antimicrobial and antioxidant activities of Feijoa sellowiana fruit. International Journal of Antimicrobial Agents, 13, $197-201$.

[9] Basile A, Conte B, Rigano D, Senatore F and Sorbo S. (2010). Antibacterial and antifungal properties of acetone extract of Feijoa sellowiana fruits and its effect on Helicobacter pylori growth. Journal of Medicinal Food 13, 189195.

[10] Weston RJ. (2010). Bioactive products from fruit of the feijoa (Feijoa sellowiana, Myrtaceae): A review. Food Chemistry, 121, 923-926.

[11] Kirchman P and Botta G. (2007). Copper supplementation increases yeast life span under conditions requiring respiratory metabolism. Mechanisms of Ageing and Development, 128, 187-195.

[12] Ito A, Nakaminami H, Wajima T and Noguchi N. (2016), Impact of calcium concentration in Muller-Hinton medium on the antimicrobial activity of daptomycin. Journal of Global Antimicrobial Resistance, 4, 76-77.

[13] De Miguel MJ, Marín CM, Muñoz PM, Dieste L, Grilló MJ and Blasco JM. (2011). Development of a selective culture medium for primary isolation of the main Brucella species. Journal of Clinical Microbiology, 49, 1458-1463.

[14] Kimura H, Nashimoto H, Shimizu M, Hattori S, Yamada K, Koba K, Yoshida N and Kato K. (2010). Microbial methane production in deep aquifer associated with the accretionary prism in Southwest Japan. The ISME Journal, 4, 531-541.

[15] Renouf V and Lonvaud-Funel A. (2007). Development of an enrichment medium to detect Dekkera/Brettanomyces bruxellensis, a spoilage wine yeast, on the surface of grape berries. Microbiological Research, 162, 154-167.

[16] Parekh J, Karathia N and Chanda S. (2006). Evaluation of antibacterial activity and phytochemical analysis of Bauhinia variegata l. bark. African Journal of Biomedical Research, 9.

[17] Asna Ashari M, Fayaz F, Moezzi Ghadim N, Alim Marvasti L and Mehrabi Y. (2009). Evaluation of the antimicrobial effects of MTAD, NaOCl against selected endodontic pathogens. Iranian Endodontic Journal, 4, 63-68.

[18] Ranjbar R, Arjomandzadegan M and Hosseiny H. (2017). Evaluation of antioxidant activity and growth control properties of nanoscale structure produced from Aloe vera var. littoralis extract on clinical isolates of Salmonella. Scientia Pharmaceutica, 85.

[19] Carmen JC, Nelson JL, Beckstead BL, Runyan CM, Robison RA, Schaalje GB and Pitt WG. (2004). Ultrasonicenhanced gentamicin transport through colony biofilms of Pseudomonas aeruginosa and Escherichia coli. Journal of Infection and Chemotherapy, 10, 193-199.

[20] Parekh J, Chanda S. (2007). Antibacterial and phytochemical studies on twelve species of Indian medicinal plants. African Journal of Biomedical Research, 10.

[21] Kobayashi I, Muraoka H, Saika T, Nishida M, Fujioka T and Nasu M. (2004). Micro-broth dilution method with airdried microplate for determining MICs of clarithromycin and amoxycillin for Helicobacter pylori isolates. Journal of Medical Microbiology, 53, 403-406.

[22] Nakashima H. (2001). Biological activity of Feijoa peel extracts. Occasional Papers of the Kagoshima University Research Center for the Pacific Islands, 34, 169-175.

[23] Motohashi N, Kawase M, Shirataki Y, Tani S, Saito S, Sakagami H, Kurihara T, Nakashima H, Wolfard K, Mucsi I, Varga A and Molnár J. (2000). Biological activity of Feijoa peel extracts. Anticancer Research, 20, 4323-4329.

[24] Dohou R, Yamni K, Tahrouch S, Hassani LI, Badoc A and Gmira N. (2003). Screening phytochimique d'une endémique iberomarocaine, Thymelaea lythroides. Bulletin of the Bordeaux Pharmacy Society 142, 61-78.

[25] Monforte M, Lanuzza F, Mondello F and Pergolizzi S. (2014). Phytochemical composition and gastroprotective effect of Feijoa sellowiana Berg fruits from Sicily. Journal of Coastal Life Medicine, 2(1), 14-21. 
[26] Weston RJ. (2010). Bioactive products from fruit of the feijoa (Feijoa sellowiana, Myrtaceae): A review. Food Chemistry, 121, 923-926.

[27] Basile A, Vuotto ML, Violante U, Sorbo S, Martone G and Castaldo-Cobianchi R. (1997). Antibacterial activity in Actinidia chinensis, Feijoa sellowiana and Aberia caffra. International Journal of Antimicrobial Agents, 8, 199-203.

\section{How to cite this article}

Elfarnini M, Abdel-hamid AA, Achir M, Jamaleddine J and Blaghen M. (2018). Antibacterial and antifungal activities of hexane and acetone extracts of sheets and fruits of Feijoa sellowiana O. GSC Biological and Pharmaceutical Sciences, $3(1), 35-44$. 